\title{
Wealth and Income Inequality in Europe
}

While it has long been apparent that global levels of wealth and income inequality have been steadily increasing since the 1970s, the issue received scant attention in Europe until the recent financial crisis and the resulting Great Recession illuminated for the general public just how great the chasm between the very rich and everybody else had grown. This realisation was coupled with an increased focus on inequality among economists and other academics, leading to a fresh drive for policy ideas to remedy the alarming trend. This Forum comprises a diverse range of viewpoints on the recent history and dynamics of inequality within Europe, each striving to define the root causes in the various countries being examined. The definition of these causes, of course, can inform the direction of policies aimed at alleviating the growing inequality in many European countries and thereby curtail one of the major political and social issues of our time.

The Engines of Inequality

Maurizio Franzini, Sapienza University of Rome, Italy.

Mario Pianta, Università di Urbino, Italy.

Causes of Changing Inequality in the World

James K. Galbraith, University of Texas, Austin, TX, USA.

Wealth Inequality and the Great Recession

Francesco Bogliacino, Universidad Nacional de Colombia, Bogota, Colombia.

Virginia Maestri, European Commission, Joint Research Centre, Seville, Spain.

Income Inequality in Europe Since the Crisis

Michele Raitano, Sapienza University of Rome, Italy.

The Erosion of the German Middle Class

Gerhard Bosch, University of Duisburg-Essen, Germany.

Thorsten Kalina, University of Duisburg-Essen, Germany. 